\title{
Pengaplikasian Building Information Modeling (BIM) Dalam Desain Bangunan Gedung
}

\author{
Senot Sangadji1), S.A. Kristiawan ${ }^{2)}$, dan Inton Kurniawan Saputra. ${ }^{3)}$ \\ 1) Pengajar Fakultas Teknik, Prodi Teknik Sipil, Universitas Sebelas Maret \\ 2) Pengajar Fakultas Teknik, Prodi Teknik Sipil, Universitas Sebelas Maret \\ 3) Mahasiswa Fakultas Teknik, Prodi Teknik Sipil, Universitas Sebelas Maret \\ Jl. Ir. Sutami 36A, Surakarta 57126; Telp. 0271-634524. Email: intonkurniawan@gmail.com
}

\begin{abstract}
There are various types of conflicts in the construction process generally occur due to miss understanding, miss coordination, not have enough money, not have enough time, etc. To solve these conflicts, a technology approach is needed. After several experiments, the new innovation with a technological approach found called Building Information Modeling or as known BIM. With BIM, construction work can be finish more easily, efficiently, and on target. This method of this study is made a planning of the building model. Then, some components of the model that are replaced in order to get more advantages of system BIM works. From the results of the analysis and discussion, it can be concluded that the BIM is a work system that integrated and make a change of component automatically in the entire building.
\end{abstract}

Keywords: Building Information Modeling (BIM), integrated, automatic

\begin{abstract}
Abstrak
Berbagai macam konflk dalam proses konstruksi, umumnya terjadi karena ketidakpahaman, kurang koordinasi, kekurangan biaya, kekurangan waktu, dan sebagainya. Untuk menyelesaikan konfik-konflik tersebut perlu pendekatan teknologi. Setelah berbagai percobaan, maka munculah sebuah inovasi dengan pendekatan teknologi bernama Building Information Modeling atau disebut BIM. Dengan BIM, pekerjaan konstruksi dapat dikerjakan dengan lebih mudah, efesien, dan tepat sasaran. BIM terdiri beberapa klasifikasi menurut fungsinya. Metode studi ini dilakukan dengan membuat perencanaan model bangunan. Kemudian ada komponen dari model tersebut yang diganti guna mendapatkan kelebihan dari cara kerja BIM. Dari hasil analisis dan pembahasan, dapat disimpulkan bahwa sistem kerja BIM adalah sistem kerja yang berintegrasi dan perubahan suatu komponen dapat dilakukan secara otomatis pada seluruh bangunan.
\end{abstract}

Kata kunci : Building Information Modeling (BIM), integrasi, otomatis

\section{PENDAHULUAN}

Bayangkan jika kita mendapatkan proyek di Kota Solo, Jawa Tengah. Arsitek berada di Kota Medan, Sumatera Utara. Designer/Engineer berada di Kota Manokwari, Papua Barat. Dan owner berada di Labuan Bajo, Nusa Tenggara Timur. Ada mungkin beberapa pertanyaan yang akan muncul, seperti, bagaimana cara untuk menjalankan proyek dengan baik namun terhalang oleh jarak bahkan bahasa? Bagaimana cara untuk menyatukan stakeholders agar tidak terjadi miss communication? Dengan cara kerja atau sistem seperti apa? Untuk menyelesaikan permasalahan tersebut, maka diperlukan cara kerja atau sistem yang terintegrasi antar satu dengan lainnya. Sistem itu bernama Building Information Modeling (BIM).

\section{LANDASAN TEORI}

Building Informaton Modeling (BIM) adalah konsep atau cara kerja menggunakan permodelan 3D digital (virtual) yang di dalamnya berisi semua informasi permodelan yang terintegrasi untuk fasilitas koordinasi, simulasi, serta visualisasi antar semua pihak yang terkait, sehingga dapat membantu owner dan penyedia layanan untuk merancang, membangun, serta mengelola bangunan. BIM diklasifikasikan menjadi beberapa bagian menurut fungsinya yaitu :

1. 2D : Model didesain dalam bentuk sketsa berisi ukuran panjang dan lebar yang tertuang pada sebuah kertas

2. 3D : Desain dari model 2D dibentuk menjadi suatu model bangunan yang dapat dilihat secara keseluruhan Model 3D bermanfaat untuk koordinasi dan mendeteksi resiko clash layanan di gedung.

3. 4D : Model 3D dihubungkan ke jadwal pembangunan. Proses ketika menambahkan parameter waktu ke 3D model disebut simulasi 4D. Model 4D umumnya digunakan untuk planning dan tracking kegiatan proyek.

4. 5D : Model hasil dari integrasi desain 3D dan 4D dengan biaya, terkait dengan komponen-komponen model. Model 5D ini digunakan untuk estimasi biaya.

Dengan perkembangan zaman dan perkembangan teknologi yang pesat, tidak memungkinkan untu kedepannya akan muncul model $6 \mathrm{D}, 7 \mathrm{D}$, dan seterusnya. Untuk menunjang sistem diperlukan software yang membantu sistem 
BIM. BIM mencakup seluruh lingkup kegiatan bangunan mulai dari desain hingga operasional dan dibagi menjadi lebih spesifik pada setiap fasenya seperti pada Gambar 1.

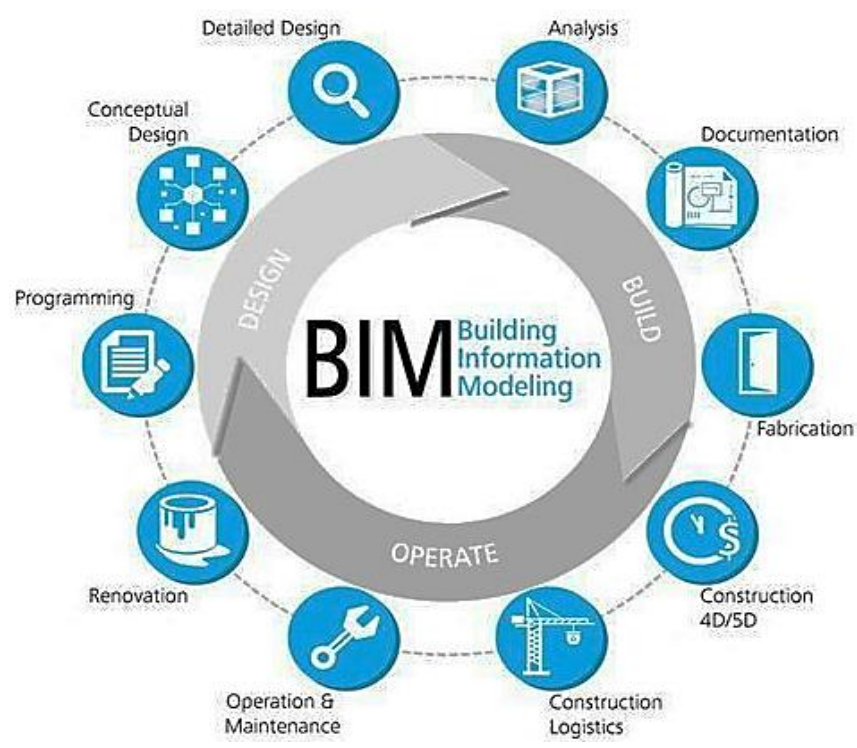

Gambar 1. Lifecycle Building

\section{METODE}

Metode yang digunakan dalam penelitian ini adalah metode perencanaan dengan beberapa kasus. Kasus pertama yaitu mengimplementasikan BIM pada sebuah desain gedung. Kasus kedua yaitu mengeksplorasi kemampuan BIM dengan cara mengganti kolom persegi degan ukuran $60 \times 60 \mathrm{~cm}$ menjadi kolom lingkaran berdiameter $60 \mathrm{~cm}$. Dan untuk kasus ketiga yaitu mengeksplorasi kemampuan BIM dengan cara mengganti penutup lantai dari kayu menjadi penutup lantai dari keramik roman. Untuk hasil akhir dari ketiga kasus ini adalah rekapitulasi anggaran biaya (RAB) pada masing-masing kasus. Spesifikasi umum dari model yaitu kuat tekan beton sebesar 41,5 MPa, kuat leleh tulangan utama sebesar $420 \mathrm{MPa}$ dengan diameter $29 \mathrm{~mm}$, kuat leleh tulangan sengkangkan sebesar $300 \mathrm{MPa}$ dengan diameter $10 \mathrm{~mm}$, dan untuk tulangan pelat memakai kuat leleh tulangan sebesar $300 \mathrm{MPa}$ dengan diameter $10 \mathrm{~mm}$.

\section{HASIL DAN PEMBAHASAN}

Hasil dan pembahasan dari kasus 1 akan dijelaskan pada Gambar 2 dan penjelasan alur pengeraannya akan dibahas pada Tabel 1 berikut ini. 


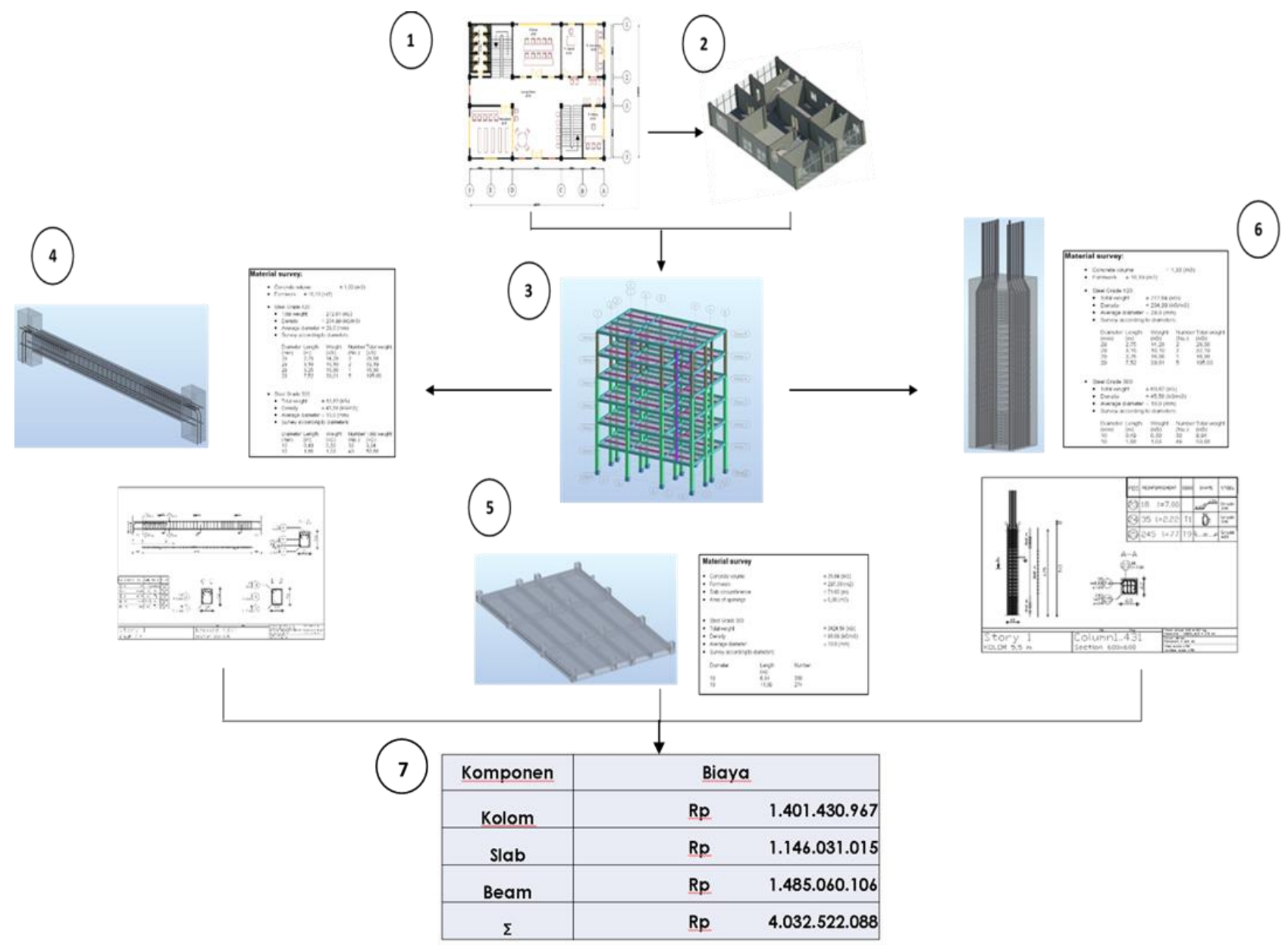

Gambar 2 Diagram Alur Pembahasan Kasus I

Tabel 1 Penjelasan Diagram Alur Kasus I

\begin{tabular}{cl}
\hline Alur & \multicolumn{1}{c}{ Penjelasan } \\
\hline $\mathbf{1}$ & Membuat sketsa desain gedung yang akan dibangun di AutoCAD \\
\hline $\mathbf{2}$ & Memodelkan sketsa ke desain model 3D di Autodesk Revit \\
\hline $\mathbf{3}$ & Mengintegrasikan model 3D ke model struktur di Autodesk. Robot Structural Analysis \\
\hline $\mathbf{4}$ & Menentukan tulangan, material survey, dan detailing balok di Autodesk Robot Structural Analysis \\
\hline $\mathbf{5}$ & Menentukan tulangan dan material survey pelat di Autodesk Robot Structural Analysis \\
\hline $\mathbf{6}$ & Menentukan tulangan, material survey, dan detailing balok di Autodesk Robot Structural Analysis \\
\hline $\mathbf{7}$ & Merancang RAB bangunan berdasrkan hasil dari material survey dengan harga di lokasi proyek \\
\hline
\end{tabular}

Hasil dari kasus I adalah total biaya yang akan dikeluarkan untuk membangun gedung secara struktural (tanpa tangga dan pondasi) sebesar Rp 4.032.522.088 (empat milyar tiga puluh dua juta lima ratus dua puluh dua ribu dan delapan puluh delapan rupiah). 
Hasil dan pembahasan dari kasus II akan dijelaskan pada Gambar 3 dan penjelasan alur pengeraannya akan dibahas pada Tabel 2 berikut ini.

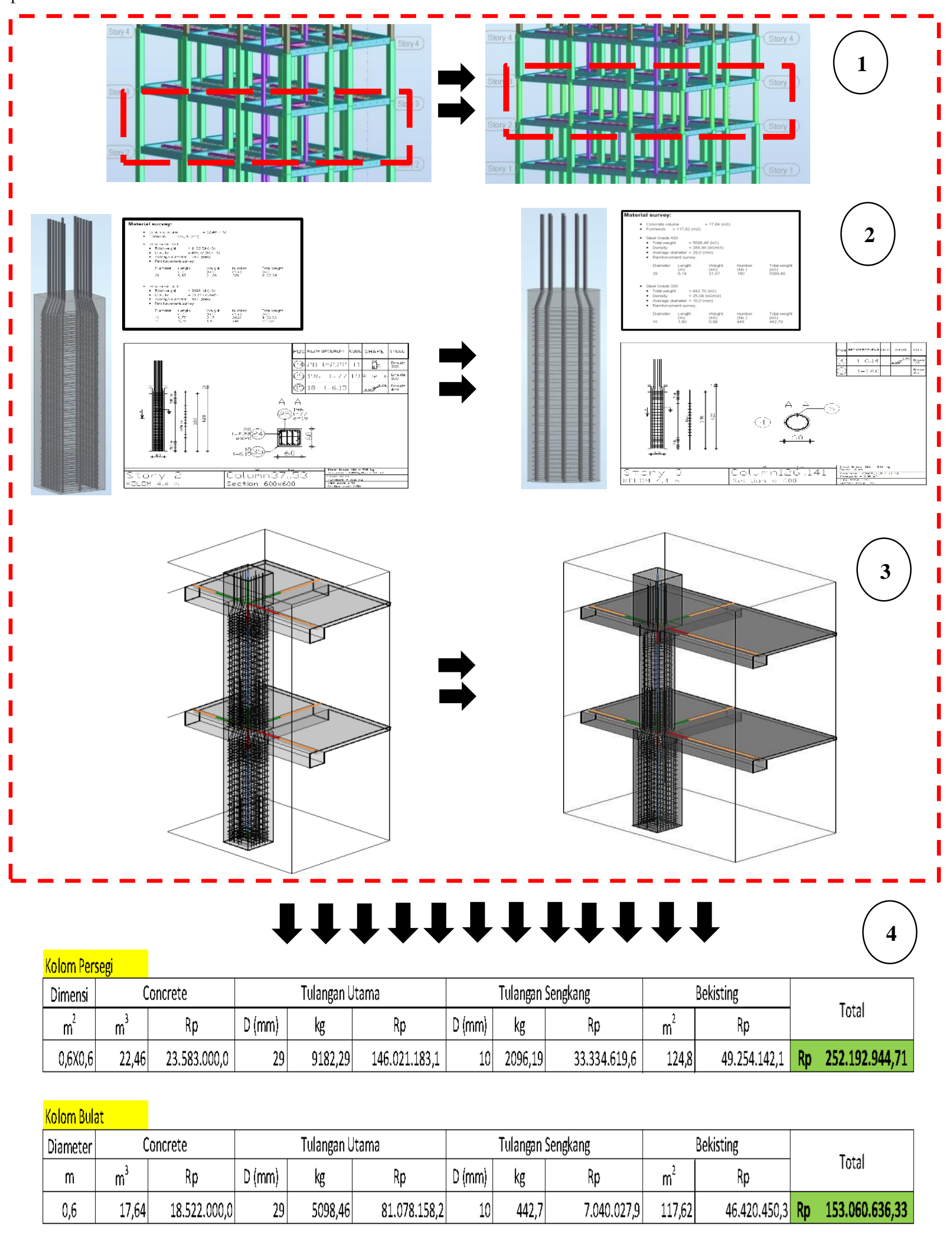


Gambar 3 Diagram Alur Pembahasan Kasus II

Tabel 3 Penjelasan Diagram Alur Kasus II

\begin{tabular}{cl}
\hline Alur & \multicolumn{1}{c}{ Penjelasan } \\
\hline $\mathbf{1}$ & Mendesain kolom yang akan diubah di lantai II dari kolom persegi ke kolom lingkaran \\
\hline $\mathbf{2}$ & $\begin{array}{l}\text { Menganalisis dan menentukan tulangan, material survey, dan detailing baik kolom persegi maupun kolom } \\
\text { lingkaran di Autodesk Robot Structural Analysis }\end{array}$ \\
\hline $\mathbf{3}$ & Mengintegrasikan file ke Autodesk Revit untuk visualisasi \\
\hline $\mathbf{4}$ & Merancang RAB bangunan berdasarkan hasil dari material survey dengan harga di lokasi proyek \\
\hline
\end{tabular}

Hasil dan pembahasan dari kasus III akan dijelaskan pada Gambar 4.

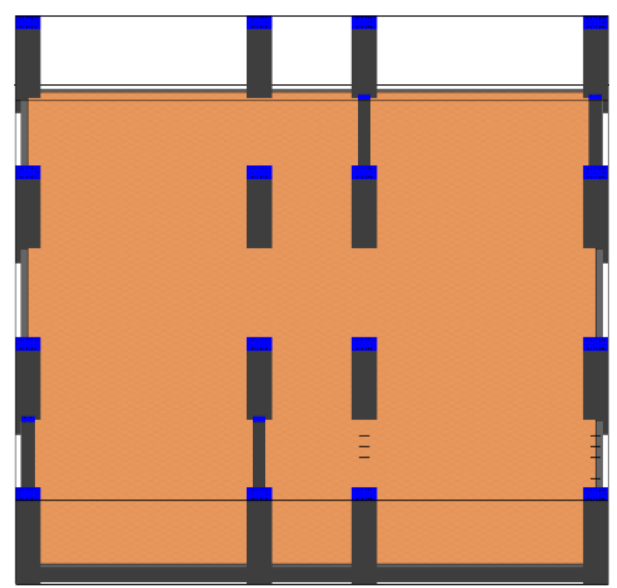

\section{Penutup Lantai dari Kayu Merbau}

Ukuran $5 \times 50 \mathrm{~cm}$, ketebalan $1 \mathrm{~cm}$.

Harga kayu sebesar Rp $150.000 / \mathrm{m}^{2}$

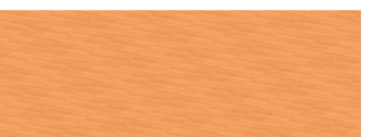

\begin{tabular}{|c|c|c|c|}
\hline \multicolumn{4}{|c|}{$\langle$ Floor Schedule $>$} \\
\hline$A$ & B & C & D \\
\hline Family and Type & Area & Cost & Total \\
\hline \multicolumn{4}{|c|}{ Floor. Kayu $10 \times 50 \times 500$} \\
\hline Floor. Kayu 10x50x & & 150000 & 44550000 \\
\hline
\end{tabular}

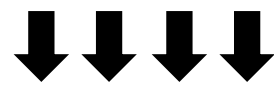

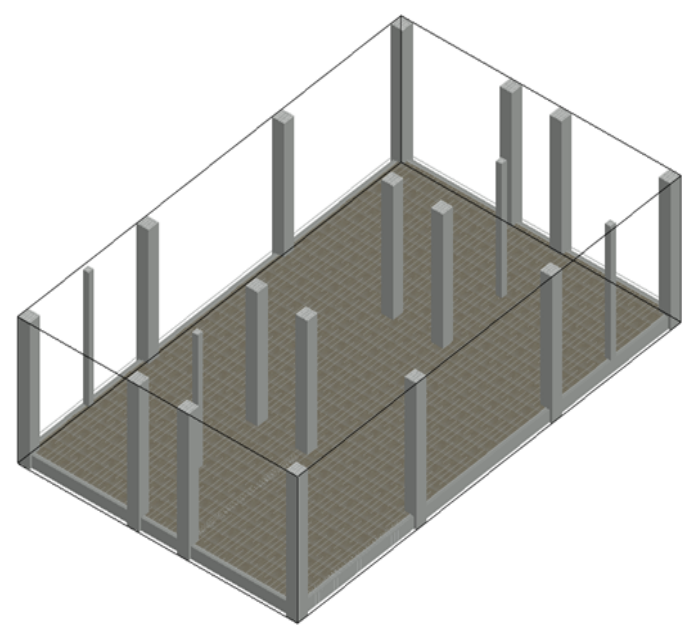

Penutup Lantai dari Keramik Roman

Ukuran 60x60 cm, ketebalan $1 \mathrm{~cm}$.

Harga keramik sebesar Rp 132.500/m²

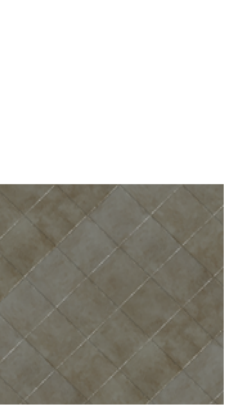

\begin{tabular}{|c|c|c|c|}
\hline \multicolumn{4}{|c|}{$<$ Floor Schedule $>$} \\
\hline $\mathrm{A}$ & $B$ & $C$ & D \\
\hline Family and Type & Area & Cost & Total \\
\hline \multicolumn{4}{|l|}{ Floor: Roman $60 \times 60$} \\
\hline Floor. Roman $60 \times 60$ & $297 \mathrm{~m}^{2}$ & 132500 & 39352500 \\
\hline Grand total: 1 & & & 39352500 \\
\hline
\end{tabular}

Gambar 4 Perbandingan Antara Penutup Lantai Kayu dan Penutup Lantai Keramik 
Dari Gambar 4 dapat ditarik kesimpulan bahwa dengan menggunakan penutup lantai keramik roman biaya untuk pembangunan dapat dihemat. Dengan menggunakan software BIM, owner lebih mudah untuk memutuskan untuk menggunakan jenis penutup lantai yang akan dipakai.

\section{SIMPULAN}

Dengan adanya sistem Building Information Modeling (BIM) pekerjaan konstruksi menjadi lebih transparan dan koordianasi menjadi mlebih cepat dan mudah. Dengan adanya integrasi antar software BIM dan otomatisasi memudahkan arsitek dan engineer untuk mengganti komponen bangunan. BIM juga membantu owner dalam proses pembuatan keputusan karena dapat melihat langsung biaya yang akan dikeluarkan dan segala pekerjaan dapat dilakukan tanpa adanya batasan jarak dan waktu antar stakeholders.

\section{REKOMENDASI}

1. BIM harus dipelajari sejak dini oleh pihak-pihak terkait bidang konstruksi karena BIM merupakan sistem kerja di masa depan.

2. Pemerintah Indonesia harus bekerja sama dengan oengaembang software BIM agar peraturan SNI dapat masuk sebagai kode di aplikasi BIM.

3. Perlunya diciptakan suatu pusat data (library) khusus untuk negara Indonesia agar pengeluaran biaya dapat diketahui secara detail.

\section{UCAPAN TERIMAKASIH}

Ucapan terima kasih pertama ditujukan kepada Tuhan Yang Maha Esa atas berkat dan karunianya. Selanjutnya kepada Bapak Dr. Senot Sangadji, S.T., M.T., dan Bapak Prof. S.A. Kristiawan, S.T., M.SC, Ph.D., selaku dosen pembimbing yang telah memberi arahan dan masukan dalam penelitian ini

\section{REFERENSI}

Nies Bradley, dan Eddy Krygiel. 2008. Green BIM : Successful Susntainable Design with Building Information Modeling. Canada: Wiley Publishing. Inc.

Nigam, Manis.dkk. 2016. BIM Vs Traditional Quantity Surveying and Its Future Mapping. IJEDR1602222, Volume 4, Issue 2, hlm.1261-1265

Kymmell, Willem. 2008. Building Information Modeling : Planning and Managing Construction Projects with 4D CAD and Simulations. USA: The McGraw-Hill Companies,Inc.

Saputra, Inton Kurniawan, dkk. 2018. Tugas Perancangan Beton. Indonesia. Program Studi Teknik Sipil Fakultas Teknik Universitas Sebelas Maret.

Smith, Peter. 2016. Project Cost Management with 5D BIM. Procedia-Sosial and Behavioral Sciences 226 (2016) 193200. 